\title{
Improving the Voltage Quality and Power Transfer Capability of Transmission System Using FACTS Controller
}

\author{
Demsew Mitiku Teferra ${ }^{1}$, Livingstone $\operatorname{Ngoo}^{2}$ \\ ${ }^{1}$ Department of Electrical Engineering, Addis Ababa Science and Technology University, Addis Ababa, Ethiopia \\ ${ }^{2}$ Department of Electrical \& Communications Engineering, Multimedia University of Kenya, Nairobi, Kenya
}

Email address:

demsewmitku@gmail.com (D. M. Teferra), livingnngoo@gmail.com (L. Ngoo)

\section{To cite this article:}

Demsew Mitiku Teferra, Livingstone Ngoo. Improving the Voltage Quality and Power Transfer Capability of Transmission System Using FACTS Controller. International Journal of Energy and Power Engineering. Vol. 10, No. 1, 2021, pp. 10-19.

doi: $10.11648 /$ j.ijepe.20211001.12

Received: November 16, 2020; Accepted: March 12, 2021; Published: March 22, 2021

\begin{abstract}
One of the main challenges of the future in the utility sector is constructing the new transmission line corridor. This is due to the fact that land compensation cost associated with the expansion of a new transmission line corridor becomes very expensive and also power transmission efficency is very low. In addition to that, the high carbon emission, which is the major challenge of the world right now, related to the additional conventional energy-based power generation to meet dramatically increased electricity demand and the volatility nature of the existing transmission networks are some of the main drivers to implement FACTS controller in transmission network for flexible, reliable, efficient and stable power transmission. This study accounts modeling of static VAR compensator (SVC), static synchronous compensator (STATCOM), unified power flow controller (UPFC) in a 5-bus transmission system to enhance transmission efficency and the quality of power supplied to the costomer. FACTS devices for improving the transmission line capacity and voltage profile of the power system. The three FACTS controllers are modeled for the standard 5 bus IEEE system based on Newton Raphson algorithm using NEPLAN simulation software in order to investigate their impacts on transmission line capacity and voltage profile improvement. Based on the simulation result, the voltage profile as well as the capacity of the IEEE 5 bus system is improved well by using each of the FACTS controller. From the simulation result we can conclude that the STATCOM and SVC are very efficent in voltge profile improvement whereas the UPFC is well performed for the power transmission capability of the transmission network.
\end{abstract}

Keywords: FACTS Controller, STATCOM, SVC, Transmission Line Capacity, UPFC, Voltage Profile

\section{Introduction}

The FACTS controller gave the opportunity to enhance the capacity of the transmission line close to its thermal limit and also increase the controllability of the power system parameters like active and reactive power flow, line current, transmission line impedance, and system operating voltage conventional power system. It has also the capability of improving the stability, power quality and reactive power imbalance of the power system [1-3, 27].

FACTS controllers are categorized as series FACTS controller (SSSC, TCSC), shunt controller (STATCOM, SVC, TCR, TSC), Series-shunt FACTS controller (UPFC, GUPFC) and Series-series FACTS controller (IPFC). Based on their control efficiency, speed of operation and cost, STATCOM, UPFC and SSSC are widely used $[1,27]$.
The main contribution of the research is implementing NEPLAN to investigate the impact of UPFC, STATCOM and SVC on the voltage quality and power transfer capability improvement of transmission line. FACTS play important role on transmission system like controlling system reliability, improving the security of the system and the efficiency of the power system. It can also provide flexibility on the controllability of power system parameters. But the scope of this study is limited to investigate the impact of UPFC, STATCOM and SVC on the voltage quality and power transfer capability improvement of transmission line. 


\subsection{Unified Power Flow Compensator}

UPFC is a series-shunt power electronics voltage source converter which is emerged as one of the most effective controllers for the control and optimization of power flow and voltage regulation in a complicated $\mathrm{AC}$ power system network. It can control three network parameters namely network impedance, current flow and system voltage independently at a time [2]. Its circuit diagram is shown in Figure 1.

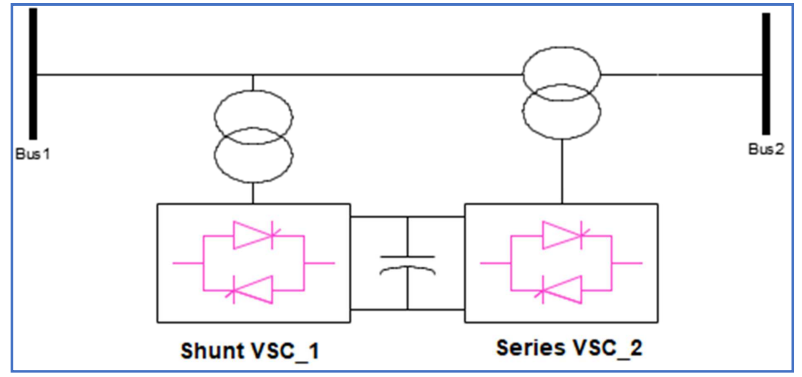

Figure 1. A UPFC Schematic Diagram.

\subsection{Static Compensator (STATCOM)}

The STATCOM is another effective but relatively cheap voltage sourced converter (VSC) as compared to UPFC and widely installed throughout the world. Figure 2 shows the STATCOM circuit. It is a shunt compensator which is installed at the bus or inserted in parallel to the transmission line through coupling transformer in order to regulate the system voltage by injecting or absorbing reactive power into or from the system which is depend on the system voltage profile. behind a coupling transformer.

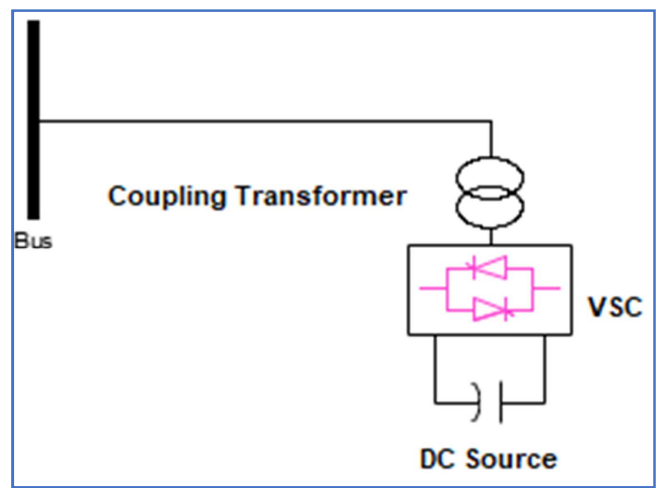

Figure 2. STATCOM Circuit Representation

The voltage source converter inside the STATCOM can produce a sinusoidal voltage of controllable magnitude and phase angle sourced from capacitor bank or energy storage system (ESS) [3, 10].

The STATCOM can operate both in the inductive and capacitive mode just like the SVC depending on the system voltage. When the system voltage, where the STATCOM is installed, is less than its nominal value, the STATCOM functioned as a capacitor to inject reactive power into the system whereas the STATCOM operates in the inductive mode to absorb extra reactive power from the system when the system voltage exceeds the nominal value so as to adjust the system voltage value within the standard limit $[3,10]$. Figure 3 demonstrates the droop characteristics of the STATCOM at deferent operation region.

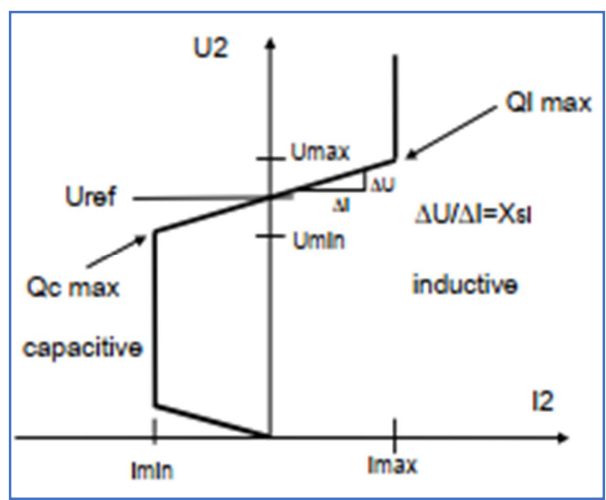

Figure 3. STATCOM V-I Characteristic Curve [3].

\subsection{Static VAR Compensator (SVC)}

SVC is thyristor controlled first generation FACTS controller shown in Figure 4. It has a very slow switching time and large size as compared to its counterpart, STATCOM.

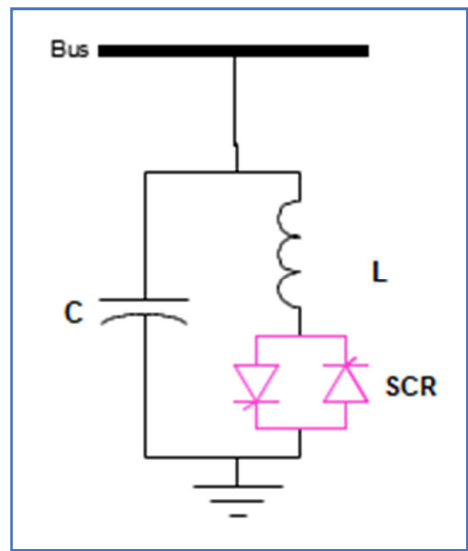

Figure 4. Typical SVC (TSC-TCR) Configuration.

It is functioned as a voltage regulator and power factor corrector for large industrial inductive loads in order to improve stability and power quality of the supply [4]-[9].

\section{Steady State Load Flow Study}

For a conventional grid, the power flow is from generation to load whereas in a modern grid consists of distributed generation the conventional power flow approach is changed. It can take place from load to generation as a bottom-up approach too [11-14].

The model of the load flow both in conventional and smart grid is done using Newton Raphson (NR) algorithm. This model is the most efficient model for both conventional and smart grid with and without the incorporation of FACTS controller. It is because of fast convergence property and a very small memory requirement $[25,28]$. 


$$
\begin{aligned}
{\left[\begin{array}{l}
\Delta P \\
\Delta Q
\end{array}\right] } & =\left[\begin{array}{ll}
J 1 & J 2 \\
J 3 & J 4
\end{array}\right]\left[\begin{array}{l}
\Delta \theta \\
\Delta V
\end{array}\right] \\
\Delta P & =P^{\text {Spec }}-P^{c a l} \\
\Delta Q & =Q^{\text {Spec }}-Q^{c a l} \\
\Delta \theta & =\theta^{(P+1)}-\theta^{(P)} \\
\Delta V & =V^{(P+1)}-V^{(P)}
\end{aligned}
$$

The Jacobean matrix elements $\mathrm{J} 1, \mathrm{~J} 2, \mathrm{~J} 3$ and $\mathrm{J} 4$ are calculated using equation (6).

$$
J_{1}=\frac{\partial P}{\partial \theta}, J_{2}=\frac{\partial P}{\partial V}, J_{3}=\frac{\partial Q}{\partial \theta}, J_{4}=\frac{\partial Q}{\partial V},
$$

Using the specified net $\mathrm{P}$ and $\mathrm{Q}$ at the generator and load buses, the new value of $\mathrm{P}$ and $\mathrm{Q}$ are calculated as:

$$
\begin{gathered}
P_{i}^{\text {cal }}=\sum_{k=1}^{n} V_{i} V_{k} Y_{i k} \cos \left\{\theta_{i}-\theta_{k}-\emptyset_{i k}\right\} \\
Q_{i}^{\text {cal }}=\sum_{k=1}^{n} V_{i} V_{k} Y_{i k} \sin \left\{\theta_{i}-\theta_{k}-\emptyset_{i k}\right\}
\end{gathered}
$$

Where, i, $k=1,2,3-n$

The voltage and phase angle errors are calculated using inverse of Jacobean matrix and the new value of $\mathrm{V}$ and $\theta$ at every $(p+1)$ iteration is calculated using equation (4) \& (5).

\section{NR Load Flow Model of FACTS}

The complexities of software codes, load flow equation and Jacobean matrix are increased manifold when FACTS are modeled in an existing Newton-Raphson power flow algorithm. So, the existing codes of NR load flow model is modified in order to customize the power flow from or into FACTS controller. It is depending on the actual FACTS device model and the types of FACTS controller. For example, UPFC can be modelled using two voltage sources, the shunt (STATCOM voltage, Vsh) and series (SSSC voltage, Vse) components, the model must account such types of features in the algorithm. [15, 23].

\subsection{UPFC Power Flow Model}

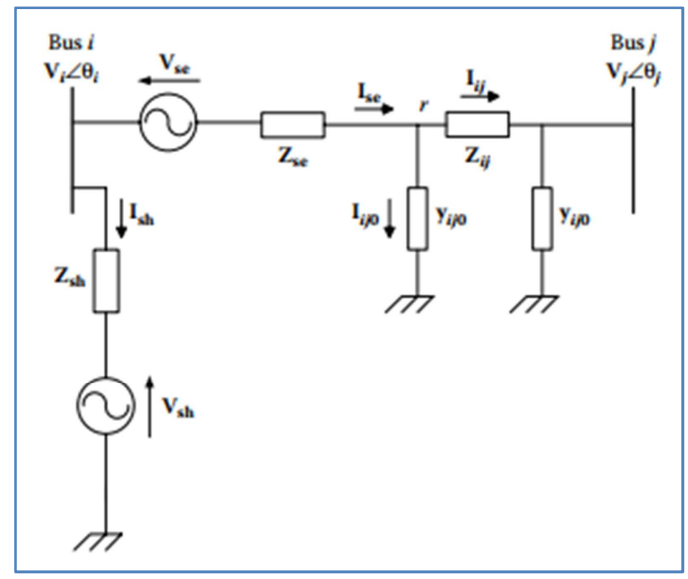

Figure 5. Equivalent circuit of the UPFC [25].

The UPFC is modelled using its shunt and series component. The shunt component is modelled using its coupling transformer impedance (Zsh) and Vsh of the VSC. The series component of the UPFC is modeled with its series injected voltage, Vse connected in series with the network impedance and coupling transformer impedance, Zse.

The circuit diagram of the UPFC is shown in Figure 5 for an $n$-bus system $[24,25]$. The net current $I i, \mathrm{P} i$ and $\mathrm{Q} i$ injected at bus $i$ incorporating UPFC at sending end of bus $i$ between bus $i$ and $j$ is computed using Equation 9-12. [18-20]

$$
\begin{gathered}
I_{i}=\sum_{k=1}^{n} V_{k} Y_{i k}+I_{s e}+I_{s h} \\
I_{s e}=\alpha_{1} V_{i}-\beta_{1} V_{j}-\alpha_{1} V_{s e}
\end{gathered}
$$

Where,

$$
\begin{aligned}
\alpha_{1}= & \frac{y_{s e}\left(y_{i j}+y_{i j o}\right)}{y_{s e}+y_{i j}+y_{i j o}} \text { and } \beta_{1}=\frac{y_{s e} y_{i j}}{y_{s e}+y_{i j}+y_{i j o}} \\
P_{i}= & \sum_{k=1, k \neq j}^{n} V_{i} V_{k} Y_{i k} \cos \left(\theta_{i}-\theta_{k}-\emptyset_{i k}\right) \\
& -V_{i} V_{j} \beta_{1} \cos \left(\theta_{i}-\theta_{j}-\emptyset_{\beta 1}\right) \\
& -V_{i} V_{s e} \alpha_{1} \cos \left(\theta_{i}-\theta_{s e}-\emptyset_{\alpha 1}\right) \\
& -V_{i} V_{s h} y_{s h} \cos \left(\theta_{i}-\theta_{s h}-\emptyset_{y s h}\right) \\
Q_{i}= & \sum_{k=1, k \neq j}^{n} V_{i} V_{k} Y_{i k} \sin \left(\theta_{i}-\theta_{k}-\emptyset_{i k}\right) \\
& -V_{i} V_{j} \beta_{1} \sin \left(\theta_{i}-\theta_{j}-\emptyset_{\beta 1}\right) \\
& -V_{i} V_{s e} \alpha_{1} \sin \left(\theta_{i}-\theta_{s e}-\emptyset_{\alpha 1}\right) \\
& -V_{i} V_{s h} y_{s h} \sin \left(\theta_{i}-\theta_{s h}-\emptyset_{y s h}\right)
\end{aligned}
$$

Using the existing NR model, the real power delivered by the UPFC placed between buses $i$ and $j$ at sending side of $i$ is:

$$
\begin{gathered}
P_{U P F C}=\operatorname{Re}\left[V_{s e}\left(-I_{s e}^{*}\right)+V_{s h}\left(-I_{s h}^{*}\right)\right] \\
P_{U P F C}=V_{s e} V_{j} \beta_{1} \cos \left(\theta_{s e}-\theta_{j}-\emptyset_{\beta 1}\right) \\
-V_{i} V_{s e} \alpha_{1} \cos \left(\theta_{s e}-\theta_{i}-\emptyset_{\alpha 1}\right) \\
-V_{i} V_{s h} y_{s h} \cos \left(\theta_{s h}-\theta_{i}-\emptyset_{y s h}\right)+V_{s h}^{2} y_{s h} \cos \left(\emptyset_{y s h}\right)+ \\
V_{s e}^{2} \alpha_{1} \cos \left(\emptyset_{\alpha 1}\right)
\end{gathered}
$$

The line active and reactive power flow with the UPFC placed between buses $i$ and $j$ at the sending end of $i$ is calculated as:

$$
\begin{gathered}
S_{i j}=V_{i} I_{i j}^{*} \\
P_{i j}=V_{i}^{2} \alpha_{1} \cos \emptyset_{\alpha 1}-V_{i} V_{j} \beta_{1} \cos \left(\theta_{i}-\theta_{j}-\emptyset_{\beta 1}\right) \\
-V_{i} V_{s e} \alpha_{1} \cos \left(\theta_{i}-\theta_{s e}-\emptyset_{\alpha 1}\right) \\
Q_{i j}=-V_{i}^{2} \alpha_{1} \sin \emptyset_{\alpha 1}-V_{i} V_{j} \beta_{1} \sin \left(\theta_{i}-\theta_{j}-\emptyset_{\beta 1}\right) \\
-V_{i} V_{s e} \alpha_{1} \sin \left(\theta_{i}-\theta_{s e}-\emptyset_{\alpha 1}\right)
\end{gathered}
$$


Now the actual Newton Raphson load flow model with UPFC is modified as [16-20].

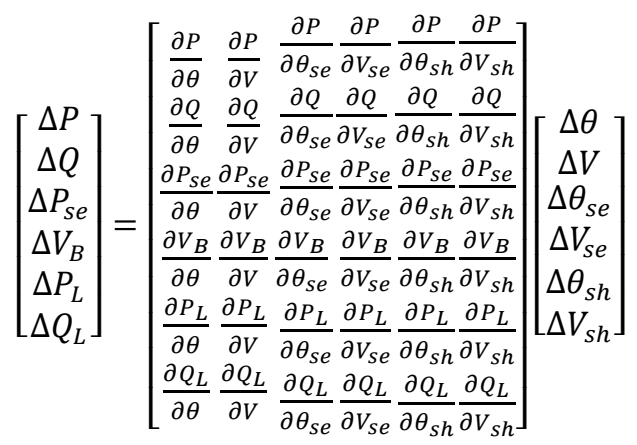

\subsection{STATCOM Power Flow Model}

The STATCOM is modelled using its shunt coupling transformer (Zsh) and voltage source converter (Vsh) as shown in Figure 6. These new terms increase the complexity of the NR load flow model of STATCOM [24, 26].

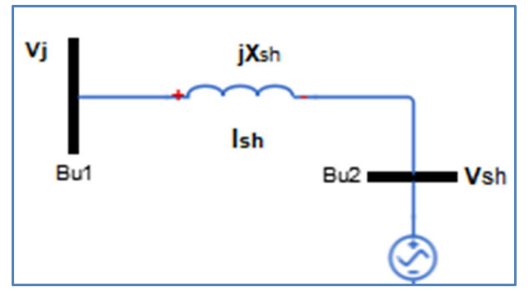

Figure 6. The STATCOM Model.

The current and the power injected at bus $j$ incorporating STATCOM at sending end terminal of bus $j$ is computed using the following Equations [26].

$$
\begin{aligned}
I_{j} & =\sum_{k=1}^{n} V_{k} Y_{j k}+I_{s h} \\
I_{s h} & =y_{s h}\left(V_{j}-V_{s h}\right)
\end{aligned}
$$

$$
\begin{aligned}
P_{j} & =\sum_{k=1}^{n} V_{j} V_{k} Y_{j k} \cos \left(\theta_{j}-\theta_{k}-\emptyset_{j k}\right) \\
& -V_{j} V_{s h} y_{s h} \cos \left(\theta_{j}-\theta_{s h}-\emptyset_{y s h}\right) \\
Q_{j} & =\sum_{k=1}^{n} V_{j} V_{k} Y_{j k} \sin \left(\theta_{j}-\theta_{k}-\emptyset_{j k}\right) \\
& -V_{j} V_{s h} y_{s h} \sin \left(\theta_{j}-\theta_{s h}-\emptyset_{y s h}\right)
\end{aligned}
$$

The real power delivered by the STATCOM connected at bus $j$ is:

$$
\begin{gathered}
P_{\text {STATCOM }}=P_{s h}=\operatorname{Re}\left[V_{s h}\left(-I_{s h}^{*}\right)\right] \\
P_{s h}=V_{s h}^{2} y_{s h} \cos \left(\emptyset_{y s h}\right) \\
-V_{j} V_{s h} y_{s h} \cos \left(\theta_{s h}-\theta_{i}-\emptyset_{y s h}\right)
\end{gathered}
$$

The NR load flow model of an n-bus system containing STATCOM is expressed using equation $(22)[24,26]$.

$$
\left[\begin{array}{c}
\Delta P \\
\Delta Q \\
\Delta P_{s h} \\
\Delta V_{b u s}
\end{array}\right]=\left[\begin{array}{cccc}
\frac{\partial P}{\partial \theta} & \frac{\partial P}{\partial V} & \frac{\partial P}{\partial \theta_{s h}} & \frac{\partial P}{\partial V_{s h}} \\
\frac{\partial Q}{\partial \theta} & \frac{\partial Q}{\partial V} & \frac{\partial Q}{\partial \theta_{s h}} & \frac{\partial Q}{\partial V_{s h}} \\
\frac{\partial P_{s h}}{\partial \theta} & \frac{\partial P_{s h}}{\partial V} & \frac{\partial P_{s h}}{\partial \theta_{s h}} & \frac{\partial P_{s h}}{\partial V_{s h}} \\
\frac{\partial V_{\text {bus }}}{\partial \theta} & \frac{\partial V_{\text {bus }}}{\partial V} & \frac{\partial V_{\text {bus }}}{\partial \theta_{s h}} & \frac{\partial V_{\text {bus }}}{\partial V_{s h}}
\end{array}\right]\left[\begin{array}{c}
\Delta \theta \\
\Delta V \\
\Delta \theta_{s h} \\
\Delta V_{s h}
\end{array}\right]
$$

\subsection{Implemented System}

The 5 bus IEEE power system implemented using the most power full power system software tool; NEPLAN was used for system simulation.

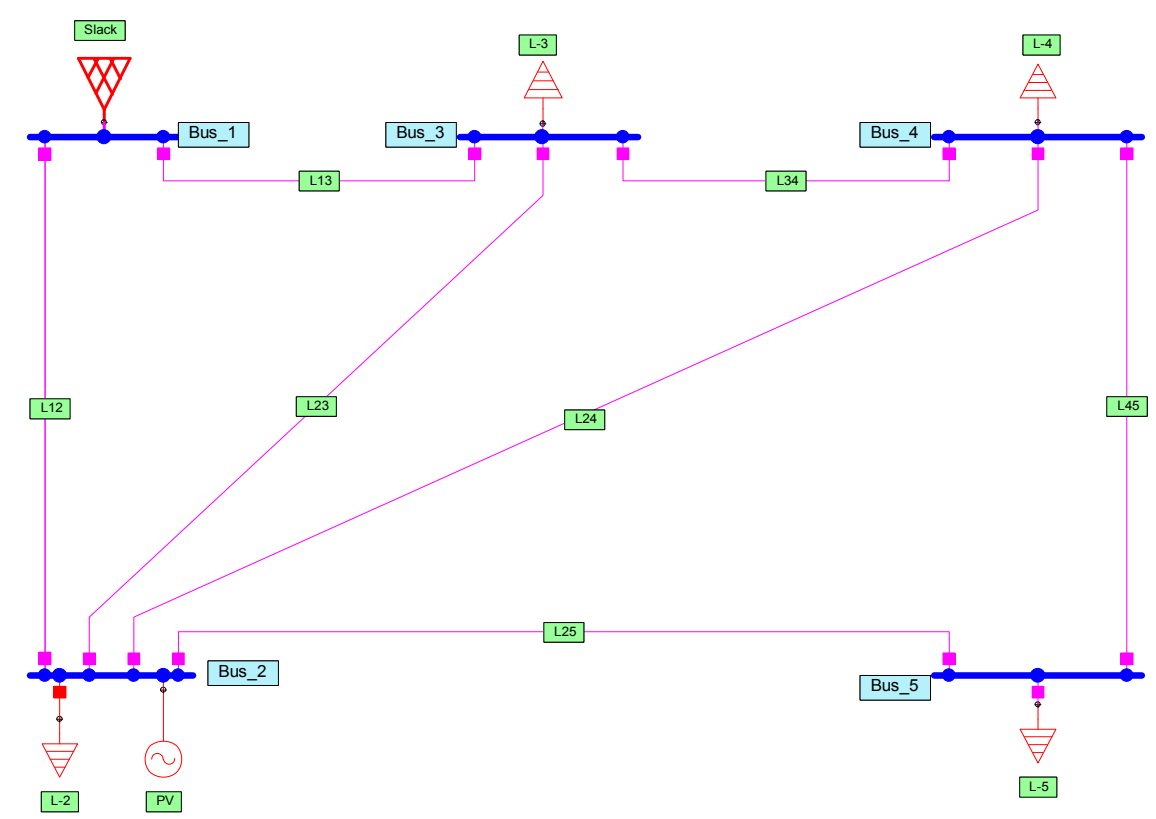

Figure 7. The 5 bus IEEE system drawn using NEPLAN. 
The 5 bus IEEE system single line diagram is shown in Figure 7. $100 \mathrm{MVA}$ and $100 \mathrm{KV}$ base values are considered to simulate the system. The load, bus, line and generator data of the 5 bus IEEE system were presented in Tables 1 and 2 .

Table 1. Bus, load and generator data.

\begin{tabular}{llllllll}
\hline Bus & $\begin{array}{l}\text { Bus } \\
\text { type }\end{array}$ & $\begin{array}{l}\text { V } \\
\text { [pu] }\end{array}$ & $\begin{array}{l}\text { Phase } \\
\text { [deg.] }\end{array}$ & $\begin{array}{l}\text { Pgi } \\
\text { [pu] }\end{array}$ & $\begin{array}{l}\text { Qgi } \\
\text { [pu] }\end{array}$ & $\begin{array}{l}\text { Pdi } \\
\text { [pu] }\end{array}$ & $\begin{array}{l}\text { Qdi } \\
\text { [pu] }\end{array}$ \\
\hline 1 & slack & 1.06 & 0 & 0.0 & 0.0 & 0.0 & 0.0 \\
2 & PV & 1 & 0 & 0.4 & 0.0 & 0.2 & 0.1 \\
3 & PQ & 1 & 0 & 0.0 & 0.0 & 0.45 & 0.15 \\
4 & PQ & 1 & 0 & 0.0 & 0.0 & 0.4 & 0.05 \\
5 & PQ & 1 & 0 & 0.0 & 0.0 & 0.6 & 0.10 \\
\hline
\end{tabular}

Table 2. Transmission line data.

\begin{tabular}{lllll}
\hline From Bus & To Bus & $\mathbf{R}[\mathbf{p u}]$ & $\mathbf{X}[\mathbf{p u}]$ & $\mathbf{B}[\mathbf{p u}]$ \\
\hline 1 & 2 & 0.02 & 0.06 & 0.06 \\
1 & 3 & 0.08 & 0.24 & 0.05 \\
2 & 3 & 0.06 & 0.18 & 0.04 \\
2 & 4 & 0.06 & 0.18 & 0.04 \\
2 & 5 & 0.04 & 0.12 & 0.03 \\
3 & 4 & 0.01 & 0.03 & 0.02 \\
4 & 5 & 0.08 & 0.24 & 0.05 \\
\hline
\end{tabular}

\subsection{Justification of FACTS Location}

The location of SVC, STATCOM, and UPFC is selected based on the bus and branch ID that have higher voltage quality issue and higher real power loss phenomena under steady state Newton Raphson load flow analysis as presented in section 4 of Table 3 and Table 4.

\section{Simulation Result}

\subsection{Simulation Result without FACTS}

The simulation result of the 5 bus IEEE power system based on newton Raphson (NR) load flow models were presented in Tables 3 and 4.

Table 3. Voltage output of the system without FACTS

\begin{tabular}{lllllll}
\hline \multirow{2}{*}{ Bus } & V2 & phase & P gen & Q gen & P load & Q load \\
\cline { 2 - 7 } & [p.u.] & {$[\mathbf{d e g}]$} & [p.u.] & [p.u.] & [p.u.] & [p.u.] \\
\hline Bus1 & 1.060 & 0.00 & 1.3112 & 0.9082 & 0.00 & 0.00 \\
Bus2 & 1.000 & -2.06 & 0.4000 & -0.616 & 0.20 & 0.10 \\
Bus3 & 0.987 & -4.64 & 0.0000 & 0.0000 & 0.45 & 0.15 \\
Bus4 & 0.984 & -4.96 & 0.0000 & 0.0000 & 0.40 & 0.05 \\
Bus5 & 0.972 & -5.76 & 0.0000 & 0.0000 & 0.60 & 0.10 \\
\hline
\end{tabular}

Table 4. Line flow of an IEEE 5 bus system.

\begin{tabular}{lllllll}
\hline \multirow{2}{*}{ From Bus } & \multirow{2}{*}{ To Bus } & \multirow{2}{*}{ Line } & P Flow & Q Flow & P Loss & Q Loss \\
\cline { 4 - 7 } & & & [p.u.] & [p.u.] & [p.u.] & [p.u.] \\
\hline Bus1 & Bus3 & 1 & 0.4179 & 0.1682 & 0.0152 & -0.0069 \\
Bus3 & Bus4 & 2 & 0.1939 & 0.0286 & 0.0004 & -0.0182 \\
Bus2 & Bus5 & 3 & 0.5466 & 0.0556 & 0.0122 & 0.0073 \\
Bus2 & Bus3 & 4 & 0.2447 & -0.0252 & 0.0036 & -0.0287 \\
Bus2 & Bus4 & 5 & 0.2771 & -0.0172 & 0.0046 & -0.0255 \\
Bus1 & Bus2 & 6 & 0.8933 & 0.7400 & 0.0249 & 0.0109 \\
Bus4 & Bus5 & 7 & 0.0660 & 0.0052 & 0.0004 & -0.0465 \\
\hline
\end{tabular}

\subsection{Simulation Result with STATCOM}

The STATCOM is placed at bus 3 shown in Figure 8 to improve the voltage. From the simulation result, the STATCOM injects 20.47 MVAR reactive power to the network at bus 3 to push the voltage of it from $0.987 \mathrm{pu}$ to 1 .

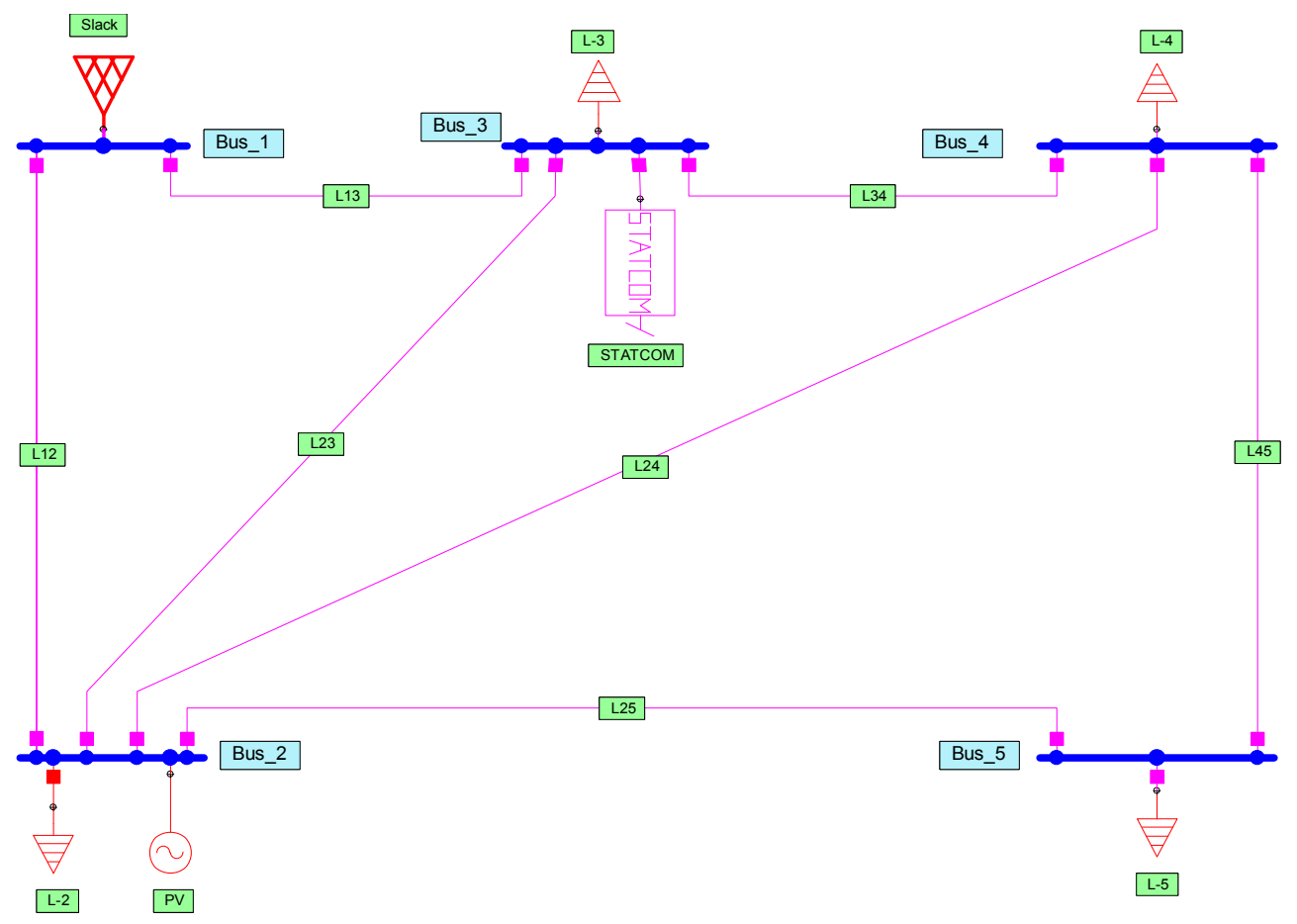

Figure 8. The IEEE-5 bus system drawn with STATCOM. 
Table 5. Voltage output of the system with STATCOM.

\begin{tabular}{lllllll}
\hline \multirow{2}{*}{ Bus } & V & phase & P gen & Q gen & P load & Q load \\
\cline { 2 - 7 } & [p.u.] & {$[\mathbf{d e g}]$} & [p.u.] & [p.u.] & [p.u.] & [p.u.] \\
\hline Bus1 & 1.060 & 0.00 & 1.31 & 0.85 & 0.00 & 0.00 \\
Bus2 & 1.000 & -2.05 & 0.40 & -0.77 & 0.20 & 0.10 \\
Bus3 & 1.000 & -4.84 & 0.00 & 0.20 & 0.45 & 0.15 \\
Bus4 & 0.994 & -5.11 & 0.00 & 0.00 & 0.40 & 0.05 \\
Bus5 & 0.975 & -5.80 & 0.00 & 0.00 & 0.60 & 0.10 \\
\hline
\end{tabular}

Table 6. Line flow result of the system with STATCOM.

\begin{tabular}{lllllll}
\hline \multirow{2}{*}{ From Bus } & \multirow{2}{*}{ To Bus } & \multirow{2}{*}{ Line } & P Flow & Q Flow & P Loss & Q Loss \\
\cline { 4 - 7 } & & & [p.u.] & [p.u.] & [p.u.] & [p.u.] \\
\hline Bus1 & Bus3 & 1 & 0.4195 & 0.1128 & 0.0139 & -0.0113 \\
Bus3 & Bus4 & 2 & 0.1965 & 0.1119 & 0.0005 & -0.0183 \\
Bus2 & Bus5 & 3 & 0.5448 & 0.0275 & 0.0119 & 0.0066 \\
Bus2 & Bus3 & 4 & 0.2449 & -0.0951 & 0.0039 & -0.0282 \\
Bus2 & Bus4 & 5 & 0.2766 & -0.0732 & 0.0048 & -0.0255 \\
Bus1 & Bus2 & 6 & 0.8911 & 0.7406 & 0.0248 & 0.0107 \\
Bus4 & Bus5 & 7 & 0.0678 & 0.0325 & 0.0006 & -0.0466 \\
\hline
\end{tabular}

As we see from the result of load flow analysis the result in Tables $5 \& 6$, STATCOM have little impact on transmission line capacity improvement rather it can effectively control the voltage at the bus bar

As we see from the result of load flow analysis the result in Tables $5 \& 6$, STATCOM have little impact on transmission line

\subsection{Simulation Result with UPFC}

The system is simulated when UPFC is placed at the sending side of bus 3 as shown in Figure 9 through the line L23. It compensates the series impedance of the line and independently controls the voltage at the buses also. The simulation result dictates the UPFC boosts the capacity of the transmission line L23 good enough.

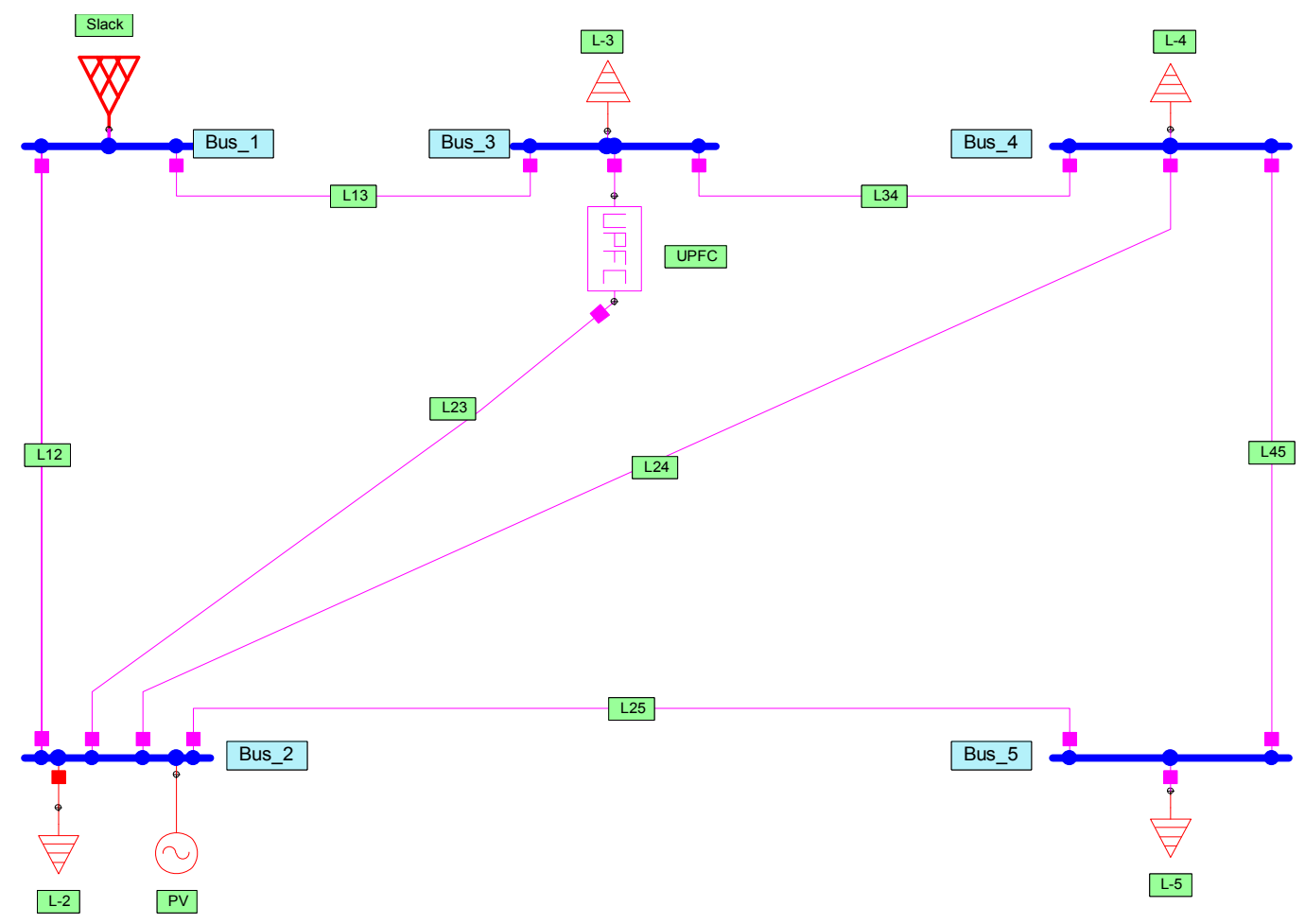

Figure 9. The 5 bus IEEE system simulated under UPFC.

Table 7. Voltage output of the system under UPFC.

\begin{tabular}{lllllll}
\hline Bus & V & phase & P gen & Q gen & P load & Q load \\
\hline & [p.u.] & [deg] & [p.u.] & [p.u.] & [p.u.] & [p.u.] \\
\hline Bus1 & 1.06 & 0.00 & 1.30 & 0.85 & 0.00 & 0.00 \\
Bus2 & 1.00 & -2.52 & 0.40 & -0.56 & 0.20 & 0.10 \\
Bus3 & 1.00 & -2.84 & 0.00 & 0.00 & 0.45 & 0.15 \\
Bus4 & 0.99 & -3.60 & 0.00 & 0.00 & 0.40 & 0.05 \\
Bus5 & 0.98 & -5.60 & 0.00 & 0.00 & 0.60 & 0.10 \\
\hline
\end{tabular}

From the simulation result, the UPFC produced 20.63 MVAR of power in order to keep the voltage value 1 p.u at bus 3 and the active power loss $0 \mathrm{MW}$ at branch L23. The UPFC also enhances the overall network capacity by $1.2 \mathrm{MW}$.
The results in Table $7 \&$ Table 8 show, UPFC could improve the voltage profile and the power transferable capacity of the transmission line.

Table 8. Line flow result of the system with UPFC.

\begin{tabular}{lllllll}
\hline From Bus & To Bus & Line & P Flow & Q Flow & P Loss & Q Loss \\
\hline & & & [p.u.] & [p.u.] & [p.u.] & [p.u.] \\
\hline Bus1 & Bus3 & 1 & 0.278 & 0.150 & 0.008 & -0.030 \\
Bus3 & Bus4 & 2 & 0.451 & 0.027 & 0.002 & -0.014 \\
Bus2 & Bus5 & 3 & 0.459 & 0.048 & 0.009 & -0.004 \\
Bus2 & Bus3 & 4 & 0.630 & 0.001 & 0.000 & 0.004 \\
Bus2 & Bus4 & 5 & 0.103 & -0.023 & 0.001 & -0.038 \\
Bus1 & Bus2 & 6 & 1.021 & 0.703 & 0.028 & 0.021 \\
Bus4 & Bus5 & 7 & 0.152 & 0.006 & 0.002 & -0.043 \\
\hline
\end{tabular}




\subsection{Simulation Result with SVC}

The static var compensator is placed at bus-3 of the IEEE system in order to examine the power transfer capability and voltage control capability of the SVC. The power system with SVC controller was shown in Figure 10 demonstrates the SVC placement in the IEEE 5 bus system drawn using NEPLAN in order to simulate its performance. Reactive power rating of the $\mathrm{SVC}$ was $\pm 100 M V A$, and the gradient of the SVC characteristic curve is $X_{s l}=25 \%$. The voltage profile and the line flow obtained after simulating the system was shown in Tables $9 \& 10$.

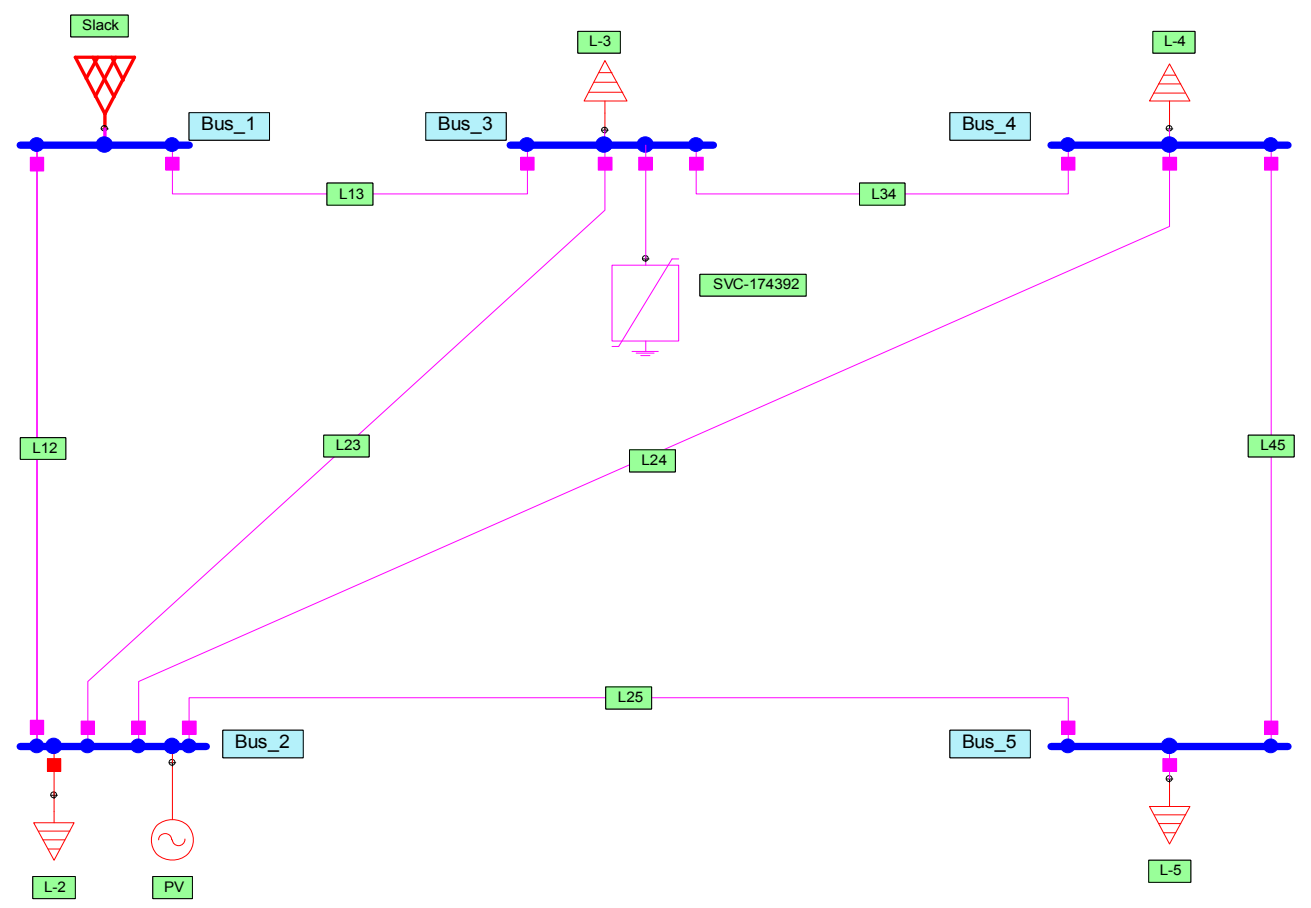

Figure 10. IEEE-5 bus power system simulated with SVC.

The NR load flow solution of the system shows that the SVC generates 20.47MVAR reactive power and operates in the inductive region to keep the voltage at bus $3,1 \mathrm{pu}$.

Table 9. Voltage output of the system with SVC.

\begin{tabular}{|c|c|c|c|c|c|c|}
\hline \multirow{2}{*}{ Bus } & V & phase & P gen & $Q$ gen & P load & Q load \\
\hline & [p.u.] & [deg] & [p.u.] & [p.u.] & [p.u.] & [p.u.] \\
\hline Bus1 & 1.060 & 0.00 & 0.131 & 0.853 & 0.000 & 0.000 \\
\hline Bus2 & 1.000 & -2.10 & 0.400 & 0.000 & 0.200 & 0.871 \\
\hline Bus3 & 1.000 & -4.80 & 0.000 & 0.000 & 0.450 & 0.150 \\
\hline Bus4 & 0.994 & -5.10 & 0.000 & 0.000 & 0.400 & 0.050 \\
\hline Bus5 & 0.975 & -5.80 & 0.000 & 0.000 & 0.600 & 0.100 \\
\hline
\end{tabular}

Table 10. Line flow result of the System with SVC.

\begin{tabular}{llllll}
\hline \multirow{2}{*}{ From Bus } & To Bus & Line & P Flow & Q Flow & P Loss \\
\cline { 4 - 6 } & & 1 & [p.u.] & [p.u.] & [p.u.] \\
\hline Bus1 & Bus3 & 2 & 0.420 & 0.113 & 0.014 \\
Bus3 & Bus4 & 3 & 0.197 & 0.112 & 0.001 \\
Bus2 & Bus5 & 4 & 0.545 & 0.028 & -0.011 \\
Bus2 & Bus3 & 5 & 0.245 & -0.109 & 0.012 \\
Bus2 & Bus4 & 6 & 0.277 & -0.073 & 0.004 \\
Bus1 & Bus2 & 7 & 0.891 & 0.741 & 0.005 \\
Bus4 & Bus5 & 0.068 & 0.033 & 0.025 \\
\hline
\end{tabular}

\section{Result Comparison}

The simulation results were presented here one with respect to the other FACTS technology to asses which technology is more effective in voltage control and which one is also more attractive in line capacity improvement.

As we seen from Figure 11. SVC, UPFC and STATCOM are good voltage controller regardless of their speed of response for dynamic nature of voltage profile variation. 


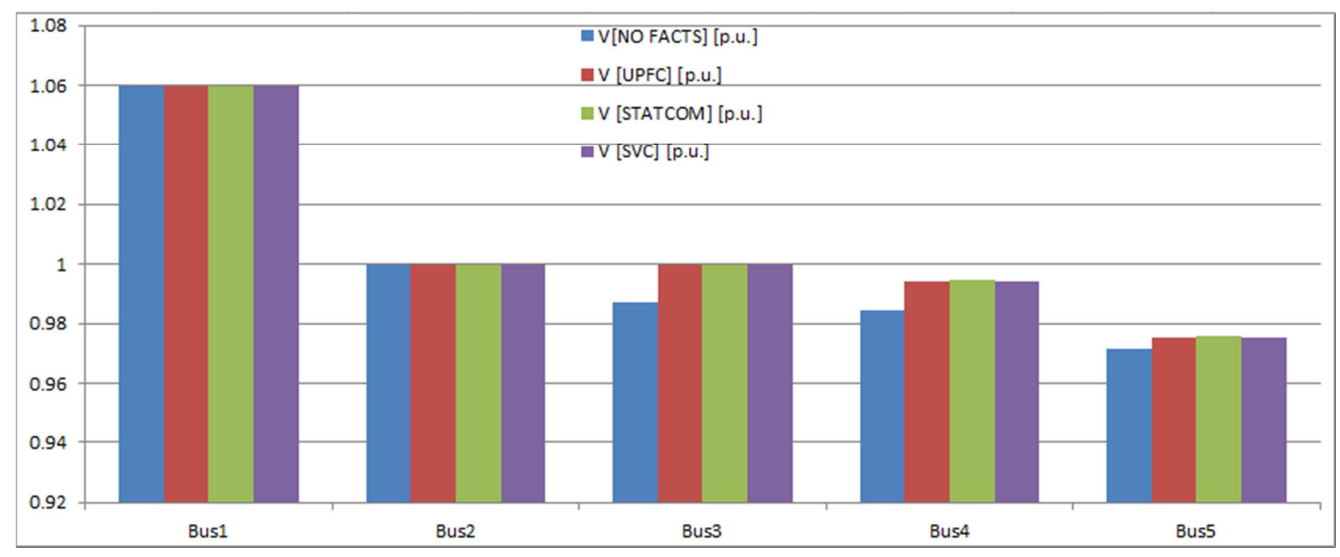

Figure 11. The Voltage output simulation result comparison of the 5 bus IEEE system using SVC, UPFC and STATCOM.

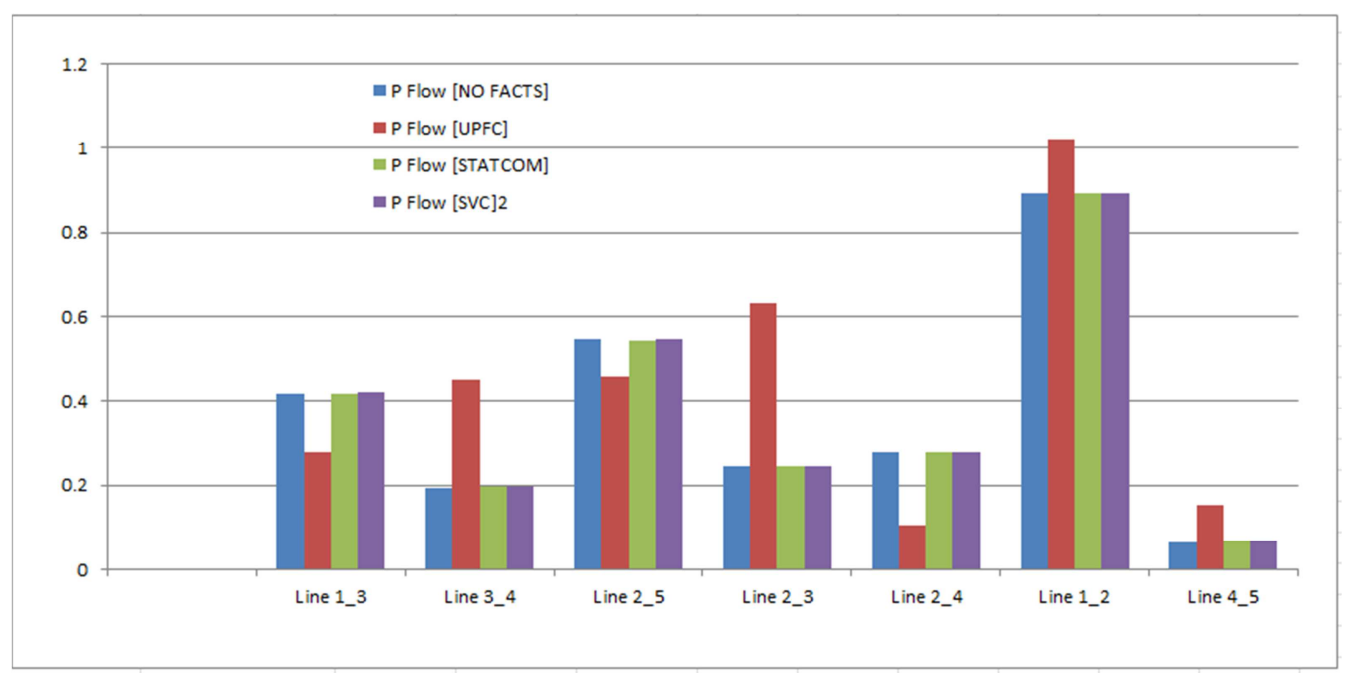

Figure 12. The line flow simulation result comparison of a 5-bus IEEE system using SVC, UPFC and STATCOM.

As we observed from Figures $12 \& 13$, the UPFC controller enhances the line capacity connected with that element but the transmission line parameter is a big matter during compensation. The transmission network power loss is also greatly reduced.

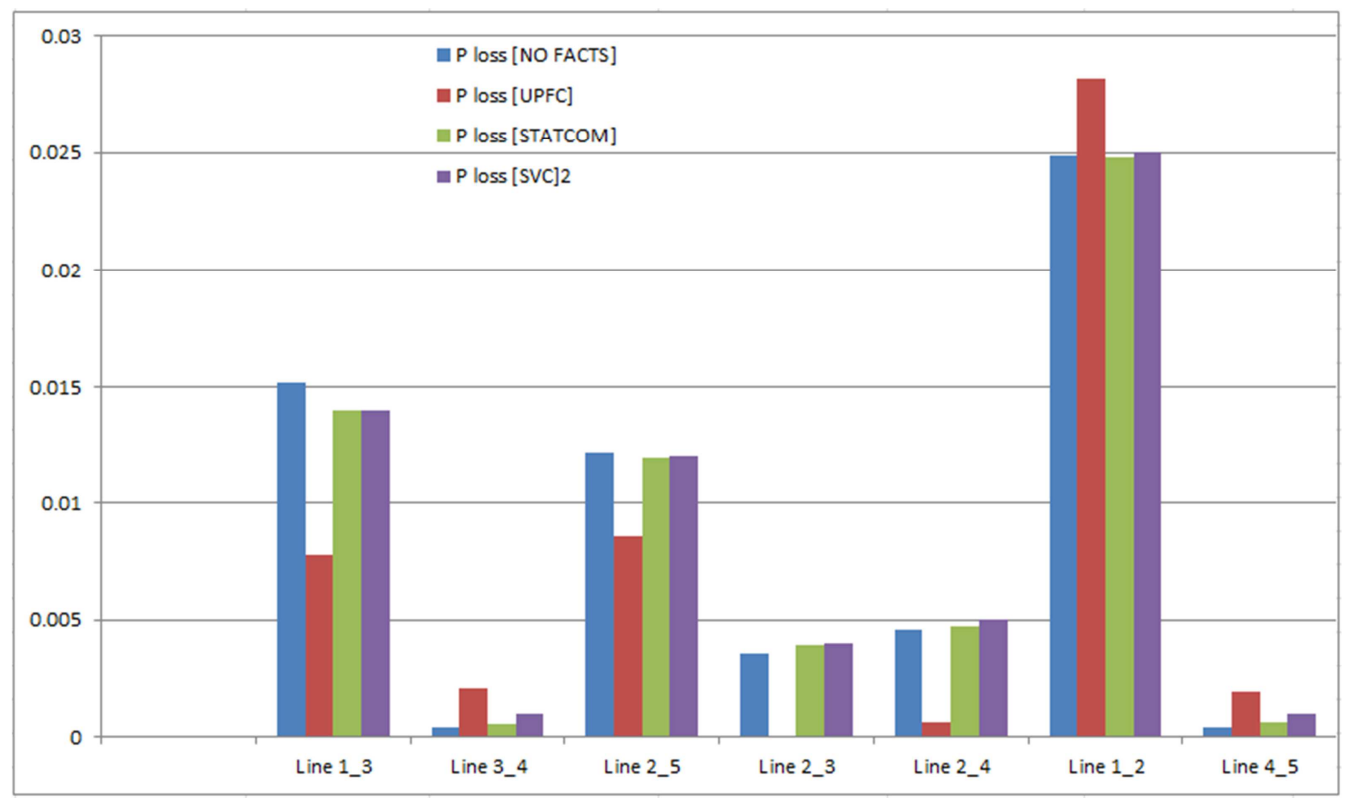

Figure 13. The line loss simulation result comparison of IEEE 5 bus system using SVC, UPFC and STATCOM. 


\section{Data Availability}

The IEEE 5 bus data is presented in Tables $1 \& 2$ but raw/processed data required to reproduce these findings cannot be shared at this time as the data also form part of an ongoing study.

\section{Summary}

As seen from the simulation result, UPFC is the best line capacity enhancer and loss absorber, whereas STATCOM and SVC are a better voltage regulator FACTS controller. Overall, the simulation result shows, FACTS controllers are capable of improving the capacity of the transmission line, the controllability of power system parameters, reducing power system network power loss and effectively controlling the system voltage magnitude and phase angle.

\section{Acronyms}

AC /Alternating Current/

ESS /Energy Storage System/

FACTS /Flexible AC Transmission System/

GUPFC /Generalized Power Flow Controller/

ID /Identification/

IEEE /Institute of Electrical and Electronics Engineers/

IPFC /Inter-line Power Flow Controller/

NR/Newton Raphson/

SSSC /Static Synchronous Series Compensator/

STATCOM /Static Compensator/

SVC /Static VAR Compensator/

TCR / Thyristor Controlled Reactor/

TCSC /Thyristor Controlled Series Compensator/

TSC /Thyristor Switched Capacitor/

UPFC /Unified Power Flow Controller/

VSC /Voltage Source Converter/

\section{References}

[1] N. G. Hingorani, L. Gyugyi, and M. El-Hawary, Understanding FACTS: Concepts and Technology of Flexible AC Transmission Systems, IEEE press, 2000.

[2] P. K. Vijay Varma1, "Load Flow Analysis in IEEE 14 Bus System Using," Ijsart, vol. 3, no. 10, 2017.

[3] K. R. Padiyar, Facts Controllers in Power Transmission Distribution. 2007.

[4] B. F. Wollenberg, "Transmission system reactive power compensation," Proc. IEEE Power Eng. Soc. Transm. Distrib. Conf., vol. 1, no. c, pp. 507-508, 2002.

[5] H. F. and S. T. A. Olwegard, K. Walve, G. Waglund, "Improvement of Transmission Capacity by Thyristor Controlled Reactive Power," IEEE Trans. Power Appar. Syst., vol. PAS-1, no. 8, pp. 3930-3939, 1981.

[6] R. M. Mathur, Static compensators for reactive power control, Canadian Electrical Association. Winnipeg: Cantext Publ.,
1986.

[7] K. R. PADIYAR and R. K. VARMA, "Concepts of Static Var System Control for Enhancing Power Transfer in Long Transmission Lines," Electr. Mach. Power Syst., vol. 18, no. 4-5, pp. 337-358, Jul. 1990.

[8] M. O'Brien and G. Ledwich, "Static reactive-power compensator controls for improved system stability," IEE Proc. C - Gener. Transm. Distrib., vol. 134, no. 1, pp. 38-42, 1987.

[9] A. E. Hammad, "Analysis of Power System Stability Enhancement by Static VAR Compensators," IEEE Trans. Power Syst., vol. 1, no. 4, pp. 222-227, 1986.

[10] X.-P. Zhang, "Fast three phase load flow methods," IEEE Trans. Power Syst., vol. 11, no. 3, pp. 1547-1554, 1996.

[11] M. S. S. and T. J. O. J. D. Glover, Power System: Analysis and Design, Fourth Ed, Thomson Learning, India. 2007.

[12] A. R. B. and V. Vittal, "Power Systems Analysis, Pearson Education." 2004.

[13] J. J. Grainger and W. D. Stevenson, Power Systems Analysis. 2004.

[14] R. Idema and D. J. P. Lahaye, Computational Methods in Power System Analysis. 2014.

[15] S. Arabi and P. Kundur, "A versatile FACTS device model for powerflow and stability simulations," IEEE Trans. Power Syst., vol. 11, no. 4, pp. 1944-1950, 1996.

[16] A. Nabavi-Niaki and M. R. Iravani, "Steady-state and dynamic models of unified power flow controller (UPFC) for power system studies," IEEE Trans. Power Syst., vol. 11, no. 4, pp. 1937-1943, 1996.

[17] M. Noroozian, L. Angquist, M. Ghandhari, and G. Andersson, "Use of UPFC for optimal power flow control," IEEE Trans. Power Deliv., vol. 12, no. 4, pp. 1629-1634, 1997.

[18] H. Ambriz-Perez, E. Acha, C. R. Fuerte-Esquivel, and A. D. la Torre, "Incorporation of a UPFC model in an optimal power flow using Newton's method," IEE Proc. - Gener. Transm. Distrib., vol. 145, no. 3, pp. 336-344, 1998.

[19] T. T. Nguyen and V. L. Nguyen, "Representation of line optimisation control in unified power-flow controller model for power-flow analysis," IET Gener. Transm. Distrib., vol. 1, no. 5, pp. 714-723, 2007.

[20] C. R. Fuerte-Esquivel, E. Acha, and H. Ambriz-Perez, "A comprehensive Newton-Raphson UPFC model for the quadratic power flow solution of practical power networks," IEEE Trans. Power Syst., vol. 15, no. 1, pp. 102-109, 2000.

[21] X.-P. Zhang and K. R. Godfrey, "Advanced unified power flow controller model for power system steady state control," in 2004 IEEE International Conference on Electric Utility Deregulation, Restructuring and Power Technologies. Proceedings, 2004, vol. 1, pp. 228-233 Vol. 1.

[22] U. Mhaskar, A. Mote, and A. Kulkarni, "A new formulation for load flow solution of power systems with series FACTS devices," in IEEE Power Engineering Society General Meeting, 2004., 2004, p. 1164 Vol. 1. 
[23] K. M. Nor, H. Mokhlis, and T. A. Gani, "Reusability techniques in load-flow analysis computer program," IEEE Trans. Power Syst., vol. 19, no. 4, pp. 1754-1762, 2004.

[24] D. M. Teferra, "Optimal Design and Dynamic Modelling of a Hybrid Distributed Generation System Containing Solar PV, Diesel and Wind Turbine with Storage," Glob. Sci. J., vol. 8, no. 2, pp. 3862-3874, 2020.

[25] S. Bhowmick, B. Das, and N. Kumar, "An Indirect UPFC Model to Enhance Reusability of Newton Power-Flow Codes," IEEE Trans. Power Deliv., vol. 23, no. 4, pp. 2079-2088, 2008.
[26] D. M. Teferra and P. D. L. Ngoo, "A Review Paper on the Role of FACTS and Resilient AC Distribution Systems in the Development of an Intelligent Power System," vol. 6, no. 6, pp. 235-243, 2019.

[27] N. G. Hingorani, "Flexible AC transmission," IEEE Spectr., vol. 30 , no. 4 , pp. 40-45, 1993.

[28] D. M. Teferra, "Potential and feasibility study of standalone solar PV/wind/biogas and biodiesel hybrid electric supply system in Ethiopia," Int. J. Energy Technol. Policy, vol. 13, no. 4, pp. 368-377, 2017. 